\title{
FLOODING IN IMAGINATION VS FLOODING IN VIVO: A COMPARISON WITH AGORAPHOBICS
}

\author{
Paul M. G. Emmelkamp and Hemmy Wessels \\ Institute for Clinical and Industrial Psychology, Trans 4, Utrecht. The Netherlands
}

(Received 25 June 1974)

\begin{abstract}
Summary-In this investigation of agoraphobic patients, 3 different fiooding procedures were compared: (1) prolonged exposure in vivo, (2) flooding in the imagination by a 'live' therapist and (3) a combination of flooding in the imagination and flooding in vivo. After an intermediate-test all clients were treated by the self-observation method. with a minimum of therapeutic intervention. Assessments were made at the beginning of treatment, during and at the end of treatment and at the follow-up one month later. Asscssments were carried out by the therapist (in tivo measurement; phobic anxiety and avoidance scales; anxious mood and panic), by an independent observer (idem. minus in vivo measurement) and by the client (phobic anxiety and avoidance scales; FSS; social anxiety scale: SDS and I-E scale). Prolonged exposure in vivo plainly proved to be superior to flooding in the imagination. Combined flooding resulted in a greater improvement than flooding in the imagination, though only on the therapist's ratings. Self-observation did not add much to the effect of prolonged exposure in vivo and of flooding combined whereas self-observation, preceded by flooding in the imagination, resulted in a significant improvement on nearly all the variables.
\end{abstract}

Recent studies have shown flooding to be an effective method in the treatment of agoraphobia. The way in which flooding was carried out differed in the various investigations. In the studies by Marks, Boulougouris and Marset (1972); Everaerd, Rijken and Emmelkamp (1973); Gelder et al. (1973); and Emmelkamp (1974 a), flooding in the imagination was combined with flooding in vivo, which makes it impossible to determine what the effect of each individual method is.

Taken individually, both flooding in the imagination (Watson and Marks, 1972) and flooding (prolonged exposure) in vivo (Hand, Lamontagne and Marks, 1974) turned out to be an effective method of treatment for agoraphobics. In the investigations of Stern and Marks (1973) and Watson, Mullett and Pillay (1973), the effect of flooding in the imagination was compared with that of flooding in vivo with agoraphobics: flooding in vivo resulting in the greatest improvement. In both investigations, however, flooding in the imagination was conducted by means of a tape-recorder. which in general has much less effect than flooding by a 'live' therapist (Marks, 1972).

Other effective methods of treatment for agoraphobia in which the clients are exposed to the phobic situation in vivo are shaping or successive approximation (Agras, Leitenberg and Barlow, 1968; Crowe et al., 1972; Everaerd et al., 1973) and self-observation (Emmelkamp and Ultee, 1974). With self-observation, the exposure to the anxiety-arousing situation is graduated and the client is instructed to return to the point of departure as soon as he begins to feel tense. The client records the time spent outside alone without feeling tense (feedback), but he receives no reinforcement from the therapist. In a study by Emmelkamp (1974 a), a comparison was made of (1) flooding, (2) self-observation, and (3) flooding followed by self-observation. The results of this study suggest that self-observation preceded by a few flooding sessions is more effective than either flooding or self-observation 
alone. In this investigation, flooding consisted of a combination of flooding in the imagination and flooding in vivo.

In the present study, 3 different flooding procedures were compared: (1) flooding (prolonged exposure) in vivo, (2) flooding in the imagination by a 'live' therapist, and (3) a combination of flooding in the imagination and flooding in vivo. All 3 procedures were followed by self-observation in order to make it possible to determine which combination had the most effect.

\section{METHOD}

\section{Design}

Clients were matched with respect to the following variables: duration of time they were able to walk around in the streets alone, duration of complaint, and sex. After the first 2 sessions, in which the assessment and the selection of cues took place, the 3 groups received treatment consisting of 4 sessions of prolonged exposure in vivo for group A. 4 sessions of flooding in the imagination for group B, and 4 sessions of combined flooding (in the imagination and in vivo) for group $C$. Following the intermediate test. each group underwent 8 self-observation sessions with a minimum of therapeutic intervention: the therapist was only present at the first 2 sessions. After these 8 sessions the post-test was carried out, and after a month without any treatment. the follow-up.

\section{Treatments}

The home of the client was used as the starting-point (cf. Everaerd et al., 1973; Emmelkamp and Ultee, 1974; Emmelkamp. 1974 a). As a rule there were 3 sessions of 90 min each per week.

A. Prolonged exposure in vivo. With prolonged exposure in vivo, the client was exposed to the phobic situation in vivo from the start. The client had to walk outside alone uninterruptedly for $90 \mathrm{~min}$ and was not allowed to take with him anything which might reduce his anxiety, such as an umbrella. a bicycle, sunglasses. a dog. etc. Therapist and client had agreed upon a route through the town, which was a difficult one and which ran in a

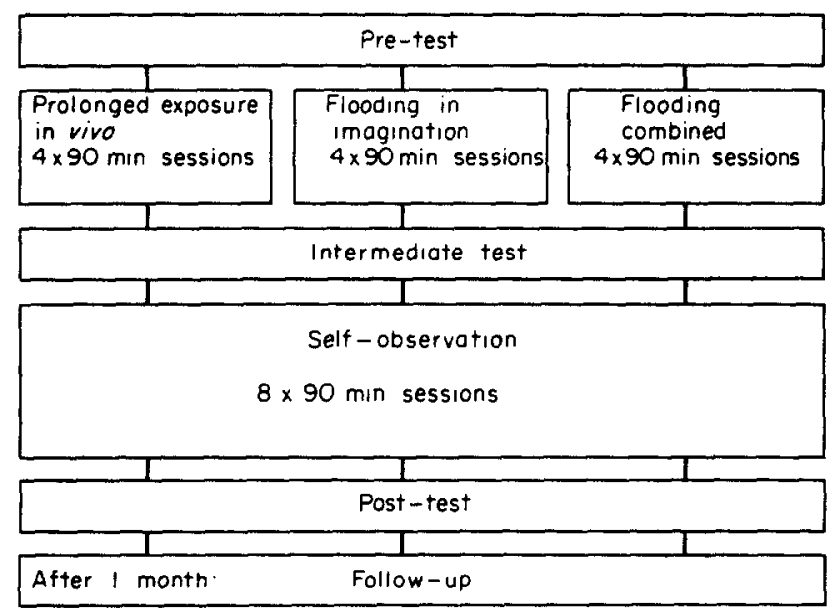

Fig. 1. Design. 
straight line in a direction away from the home of the client. Visits to department stores and bus rides were sometimes included in the route.

$B$. Flooding in the imagination. With flooding in the imagination, the client was exposed to the phobic situation in the imagination uninterruptedly for $90 \mathrm{~min}$ per session. The client was instructed to sit in a relaxed way and to close his eyes. Next. the therapist asked the client to imagine as vividly as possible the situations described by the therapist and not to avoid imagining these scenes in any way. Again and again the scenes which aroused the most anxiety in the client were described. such as walking alone in the street. sitting in a room full of people. travelling by bus. train, and so on. If certain scenes no longer aroused anxiety, changes were introduced into the scenes. No psychodynamic cues were used in the scenes.

C. Combined flooding (in the imagination and in vivo). With this treatment. the client was first exposed uninterruptedly to the phobic situation in the imagination for $45 \mathrm{~min}$; immediately after this he was exposed uninterruptedly for $45 \mathrm{~min}$ to the phobic situation in vivo. After 45 min of flooding in the imagination (identical to condition $\mathrm{B}$ ), the client had to go out into the street and walk along a route agreed upon previously.

$D$. Self-observation. After the intermediate test all clients were treated with self-observation. This technique (Emmelkamp, $1974 \mathrm{a}$ ) involves a graduated approach by the subjects into the actual feared situation, with instructions to turn back on experiencing undue anxiety. In fact, this procedure is a modification of successive approximation. The differences with the latter procedure are that the client with self-observation observes his progress by recording the time he is able to spend outside without feeling tense and that he never is reinforced by his therapist.

Right from the first session, the client had to enter the phobic situation. Therapist and client agreed upon a route through the city, difficult for the client, leading in a straight line from his home. He was given the following instructions: "You must now go into the street and stay outside until you begin to feel uncomfortable or tense. As soon as you no longer feel happy, you must come back straight-away". The client had to record the duration of each trial. After returning home for the first time he had to write down the duration in a note-book. Then he had to enter the phobic situation in the same way. This procedure was repeated until the 90 -min session was over. The therapist was present only at the first two sessions. and had been instructed to occupy himself with work of his own and to interfere with the activities of the client as little as possible. After these two sessions the client had to carry on alone. At the end of each trial he had to note down the time spent outside without feeling tense. and he had to send the results to his therapist at the end of each session. After 6 'homework' sessions the post-test was applied.

\section{Therapists}

Therapists in this investigation were either psychologists or advanced clinical psychology students; they were all versed in behaviour therapy. All the therapists were supervised by the senior author. Weekly group discussions were held at which difficulties connected with the treatments were discussed.

\section{Clients}

Twenty-six clients took part in the experiment, 24 women and 2 men. During the first phase of treatment, 3 clients decided not to continue with the treatment, leaving 22 women and 1 man. Their average age was $34.2 \mathrm{yr}$, ranging from 16 to $55 \mathrm{yr}$. The average duration 
of the complaint was $7.3 \mathrm{yr}$. ranging from 2 to $20 \mathrm{yr}$. After the intermediate test. 4 clients dropped out because they could not meet the methodological demands of the experiment.

Thus of the original 26 subjects. 18 women and 1 man completed the treatment: Dropouts were equally divided over the three conditions.

\section{Assessments}

Assessments were carried out at the pre-test. intermediate test. post-test and the followup by the client and the therapist. In addition. an independent observer-a clinical psychologist-assessed the client at the beginning and the end of the treatment.

Measurement in vivo. The client was instructed to go into the street and to stay outside until he began to feel uncomfortable or tense. then he had to come back straightaway. The duration of time spent outside was measured by the therapist.

Phobic anxiety and aroidance scales. Client. therapist and independent observer rated 5 phobic situations on 9-point scales for phobic anxiety and phobic a voidance respectively (Watson and Marks. 1971). The scores for the main phobia (street) were calculated separately: the scores for the other four phobias were added up.

Anxious mood and panic. Therapist and independent observer rated the client on 9-point scales for anxious mood and panic (Watson and Marks. 1971).

Expectancy scale. Before treatment began. clients rated how much they expected to gain from therapy on three separate scales (Stern and Marks. 1973).

Moreover. the clients filled in the following questionnaires at the pre-test, the post-test and the follow-up: Fear Survey Schedule (FSS) (Wolpe and Lang. 1964; range 76-380); Social Anxiety Scale (SAS) (Willems. Tuender de Haan and Defares. 1973; range 0-96); Internal-External Control Scale (I-E) (Rotter. 1966; range 12-71); and Self-rating Depression Scale (SDS) (Zung, 1965; range 23-92). Variations adapted for use in the Netherlands were used.

\section{RESULTS}

At the beginning of the treatment. significant differences between the various conditions were found on the phobic anxiety scale-other phobias, as rated by clicnt $(F=$ 4.19. $p<0.03)$ and therapist $(F=4.83 . p<0.02)$. and phobic avoidance scale-other phobias. as rated by client $(F=6.77, p<0.01)$ and therapist $(F=3.95, p<0.03)$. For this reason analyses of covariance were applied to the data, using the pre-test as covariate.

\section{The effect at the intermediate te'st}

The effect of each individual treatment was tested with two-tailed $t$-tests for dependent samples. At the intermediate test. both prolonged exposure in vivo and flooding combined resulted in a significant improvement on almost all variables. whereas flooding in imagination resulted only on two variables in a significant improvement (see Table 1). In order to discover whether there were any differences between the individual conditions, posthoc analyses of Scheffé were used. Prolonged exposure in vico proved to be more effective than flooding in imagination on the in cico measurement $(p<0.10)$; phobic anxiety-street, as rated by client $(p<0.01)$ and therapist $(p<0.05)$ and other phobias, as rated by the therapist $(p<0.005)$ : phobic avoidance-street. as rated by the client $(p<0.05)$ and other phobias. as rated by client $(p<0.005)$ and therapist $(p<0.025)$; and anxious mood $(p<0.10)$. Flooding combined was more effective than flooding in imagination on phobic anxiety-street $(p<0.10)$ and other phobias $(p<0.10)$; phobic avoidance-street $(p<0.10)$ 
Table 1. Effects of the treatments at the intermediate test

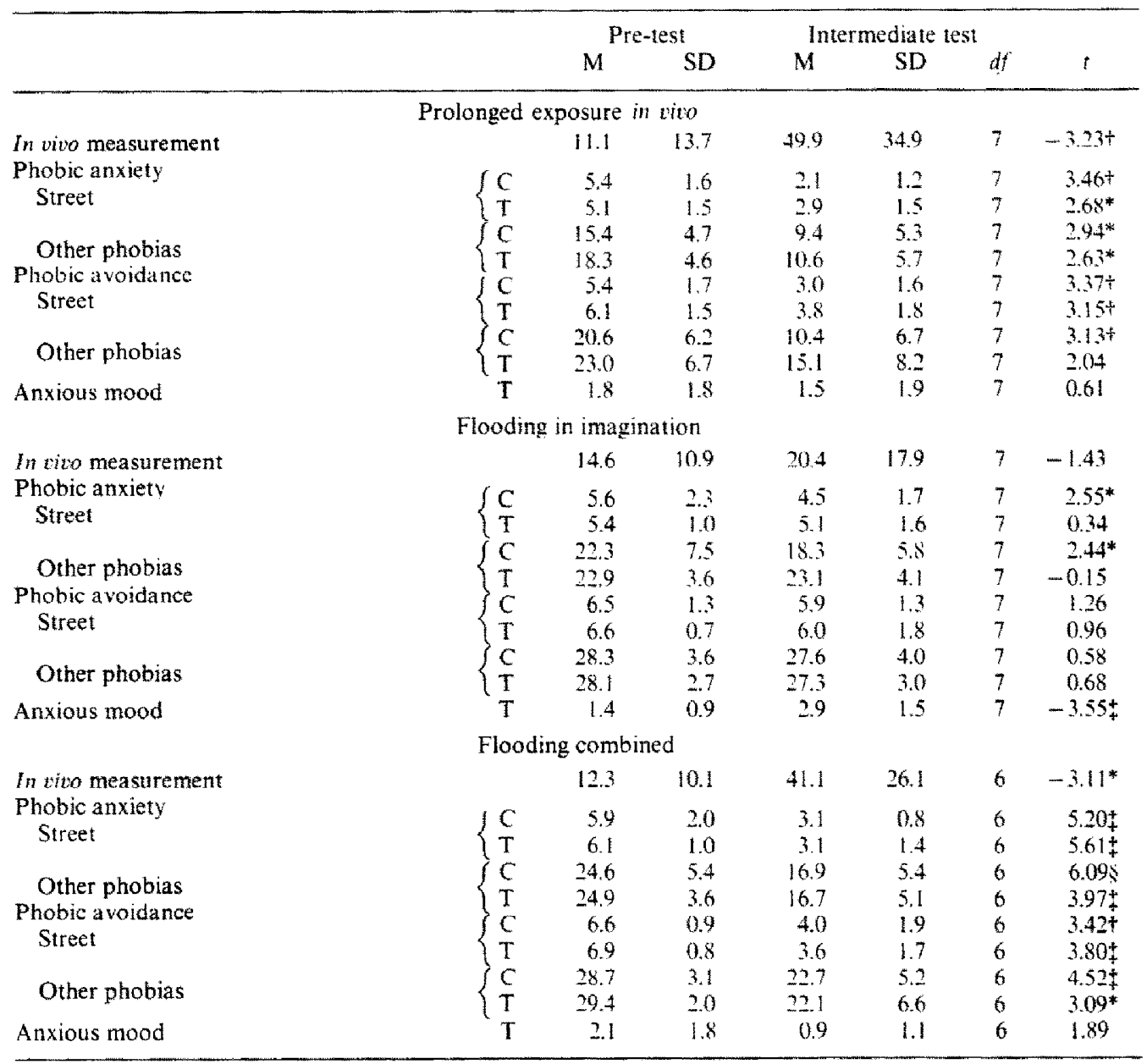

${ }^{*} p<0.05+p<0.02 \ddagger p<0.01 . \$ p<0.001$.

$\mathrm{C}=$ Client. $\mathrm{T} \ldots$ Therapist.

and anxious mood $(p<0.05$ ). all rated by the therapist. Prolonged exposure in vino proved to be more effective than flooding combined on phobic avoidance-other phobias, as rated by the client $(p<0.025)$.

The effect at the post-test

Self-observation following prolonged exposure in rivo led to a significant improvement on phobic anxiety-other phobias, as rated by the therapist $(p<0.02)$; following flooding combined on phobic avoidance-street, as rated by the therapist $(p<0.05)$ and following flooding in imagination on almost all variables: in tito measurement $(p<0.001)$; phobic anxiety - street. as rated by client $(p<0.05)$ and therapist $(p<0.01)$ and other phobias, as rated by client $(p<0.05)$ and therapist $(p<0.001)$; phobic avoidance-street, as rated by client $(p<0.05)$ and therapist $(p<0.01)$ and other phobias, as rated by client $(p<0.01)$ and therapist $(p<0.02)$. 
Table 2 contains the results from the independent observer and questionnaires. Analyses of covariance carried out on the results of the post-test did not show any significant differences between the conditions.

In the period between post-test and follow-up, no treatment took place. A comparison between the scores of the post-test and the follow-up did not yield any significant differences. Analyses of covariance on the results of the follow-up again did not show any significant differences between the conditions.

Correlation coefficients were computed between the expectancy of the client at the start of the treatment and 3 outcome measures: in vivo measurement. phobic anxiety scalestreet (therapist's and client's rating combined), and avoidance scale-street (therapist's and

Table 2. Independent Observer ratings and questionnaires

\begin{tabular}{|c|c|c|c|c|c|c|}
\hline & \multicolumn{2}{|c|}{ Pre-test } & \multicolumn{2}{|c|}{ Post-test } & \multirow[b]{2}{*}{$d t$} & \multirow[b]{2}{*}{$t$} \\
\hline & M & $\mathrm{SD}$ & M & $\mathrm{SD}$ & & \\
\hline \multicolumn{7}{|c|}{ Prolonged exposure in vivo and self-observation } \\
\hline \multicolumn{7}{|l|}{ Phobic anxiety } \\
\hline Strect & 7.3 & 0.9 & 2.9 & 2.1 & 6 & $5.45 \ddagger$ \\
\hline Other phobias & 29.3 & 2.9 & 12.6 & 9.7 & 6 & $4.00_{+}^{+}$ \\
\hline \multicolumn{7}{|l|}{ Phobic avoidance } \\
\hline Street & 6.4 & 2.0 & 2.0 & 1.6 & 6 & $4.80_{+}^{+}$ \\
\hline Other phobias & 28.4 & 3.4 & 11.9 & 9.2 & 6 & $4.24_{+}^{+}$ \\
\hline Anxious mood & 3.4 & 1.8 & 2.0 & 1.2 & 6 & $2.34^{\circ}$ \\
\hline Panic & 1.0 & 1.6 & 0.0 & 0.0 & 6 & 1.53 \\
\hline FSS & 172.7 & 23.8 & 144.9 & 14.7 & 6 & 2.22 \\
\hline SAS & 54.6 & 19.9 & 49.3 & 15.8 & 6 & 1.32 \\
\hline I-E scale & 40.9 & 8.3 & 44.3 & 6.4 & 6 & -1.69 \\
\hline SDS & 51.4 & 10.6 & 48.3 & 7.0 & 6 & 1.08 \\
\hline \multicolumn{7}{|c|}{ Flooding in imagination and self-observation } \\
\hline \multicolumn{7}{|l|}{ Phobic anxiety } \\
\hline Street & 6.7 & 1.1 & 2.7 & 2.1 & 5 & $5.48+$ \\
\hline Other phobias & 29.3 & 2.3 & 16.5 & 7.5 & 5 & $4.44_{\ddagger}^{+}-1$ \\
\hline \multicolumn{7}{|l|}{ Phobic avoidance } \\
\hline Street & 5.7 & 1.5 & 2.8 & 2.2 & 5 & $4.33_{+}^{+}$ \\
\hline Other phobias & 29.0 & 2.1 & 16.3 & 8.4 & 5 & $3.35^{*}$ \\
\hline Anxious mood & 4.7 & 1.1 & 1.8 & 1.1 & 5 & $5.94+$ \\
\hline Panic & 3.7 & 2.8 & 1.0 & 1.2 & 5 & $3.16^{*}$ \\
\hline FSS & 207.2 & 49.1 & 166.8 & 37.2 & 5 & $2.90^{*}$ \\
\hline SAS & 59.5 & 13.4 & 51.0 & 15.5 & 5 & $4.09_{+}^{+}$ \\
\hline I-E scale & 43.5 & 9.5 & 42.2 & 6.2 & 5 & 0.51 \\
\hline SDS & 52.5 & 11.0 & 45.8 & 10.0 & 5 & 1.53 \\
\hline \multicolumn{7}{|c|}{ Flooding combined and self-observation } \\
\hline \multicolumn{7}{|l|}{ Phobic anxiety } \\
\hline Street & 7.2 & 0.8 & 3.6 & 1.9 & 4 & $4.81_{+}^{+}$ \\
\hline Other phobias & 29.6 & 1.6 & 17.0 & 7.2 & 4 & $4.14 \uparrow$ \\
\hline \multicolumn{7}{|l|}{ Phobic avoidance } \\
\hline Street & 7.2 & 0.8 & 2.4 & 1.4 & 4 & 12.83 \\
\hline Other phobias & 29.0 & 2.3 & 18.2 & 4.6 & 4 & $7.38 t$ \\
\hline Anxious mood & 2.8 & 1.7 & 1.8 & 1.8 & 4 & $3.16^{*}$ \\
\hline Panic & 0.8 & 1.0 & 0.0 & 0.0 & 4 & 1.63 \\
\hline FSS & 186.8 & 44.4 & 164.5 & 50.4 & 5 & 1.35 \\
\hline SAS & 57.5 & 22.4 & 56.5 & 28.2 & 5 & 0.22 \\
\hline I-E scale & 38.2 & 11.5 & 37.8 & 10.0 & 5 & 0.21 \\
\hline SDS & 52.5 & 12.3 & 43.3 & 9.1 & 5 & 2.01 \\
\hline
\end{tabular}

${ }^{*} p<0.05 .+p<0.02 . \pm p<0.01 . \$ p<0.001$. 
client's rating combined). For the intermediate test these correlation coefficients were: in vivo measurement 0.32 , phobic anxiety $0.60(p<0.01)$, and phobic avoidance 0.46 $(p<0.05)$. For the post-test these correlations were not significant: in vivo measurement 0.21 , phobic anxiety 0.38 , and phobic avoidance 0.38 .

\section{DISCUSSION}

The results of the intermediate test clearly indicate the slight effect of flooding in the imagination and corroborate the results of studies by Stern and Marks (1973) and Watson et al. (1973). Prolonged exposure in vivo plainly proved to be superior to flooding in the imagination. Combined flooding resulted in a greater improvement than flooding in the imagination, though only on the therapist's ratings. Previous studies in which flooding in the imagination produced little or no effect have been criticized because the scenes were presented by means of a tape-recorder (Marks, 1972), or because the imagining procedure was of too short duration to produce habituation (Staub. 1968). In the present study, however, flooding in the imagination was presented by a 'live' therapist and each imagination procedure lasted $90 \mathrm{~min}$.

The two-factor theory would lead one to expect that flooding in the imagination would initially result in a reduction of the conditioned emotional response (CER), while prolonged exposure in vivo would initially result in a reduction of the conditioned avoidance response (CAR). Prolonged exposure in vivo, however, turned out to be superior to flooding in the imagination both on the phobic anxiety scales (CER) and on the phobic avoidance scales (CAR).

Another striking fact is that flooding in the imagination leads to a significant increase in anxious mood. A number of clients regarded flooding in the imagination as an irksome procedure, the sense of which they did not see: a few clients remarked that this procedure made them more rather than less anxious. One client, trcated with flooding in the imagination, reported at the follow-up that certain flooding scenes became almost an obsession with her when she was walking outside.

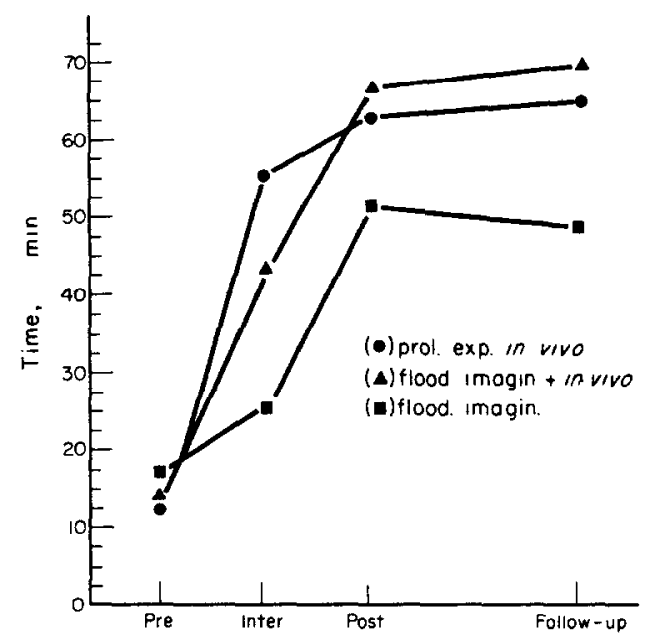

Fig. 2. The effects of the treatments on the in vivo measurement. 


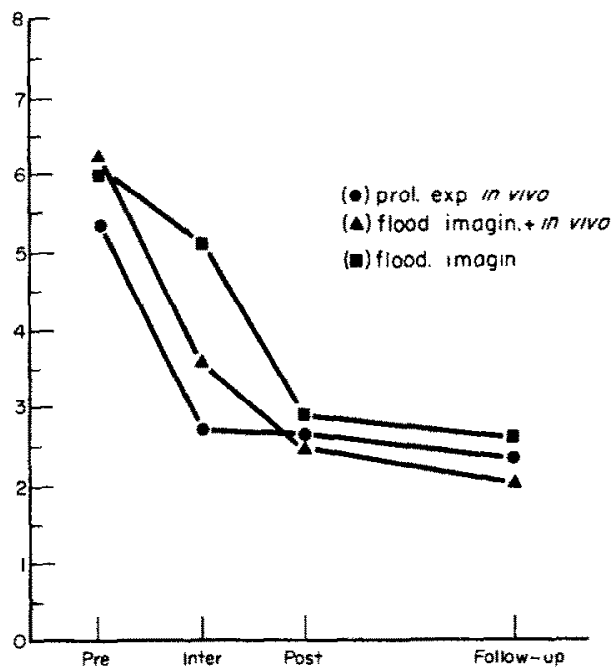

Fig. 3. The effects of the treatments on the combined phobic anxiety and phobic avoidance scalesstreet (client's and therapist's rating combined).

Although it was obvious that prolonged exposure in vivo was definitely a superior procedure to flooding in the imagination, it can be too terrifying for some clients. One client, for instance, hid in the cellar out of fear of being sent into the street for $90 \mathrm{~min}$ by the therapist. Possibly, prolonged exposure in vivo in groups or with medication might offer a solution for clients such as this one.

Self-observation, preceded by flooding in the imagination. resulted in a significant improvement on nearly all the variables: during self-observation clients improved to a much greater extent than during flooding in the imagination (see Figs. 2 and 3). Self-observation did not appear to add much to the effect of prolonged exposure in vivo and of flooding combined: after both procedures, the clients had already improved to such an extent that any further improvement could hardly have been expected. With the self-observation procedure, the client carries out the treatment himself; in this respect this procedure differs from the flooding (in the imagination or in vivo) procedures. Taking into account the positive correlations found between phobic anxiety and external locus of control (Emmelkamp and Cohen-Kettenis, 1974), a shift from therapist-control to self-control could be a factor which, especially with this group of clients. might be introduced into the therapeutic strategy.

In spite of the large number of analogue studies carried out with students suffering from relatively insignificant phobias, it is still not clear what the influence of the client's expectancy of therapeutic gain is on behaviour-therapeutic procedures (Borkovec, 1973; Wilkins, 1973; Emmelkamp, 1974 b). In the present investigation. significant correlations were found between expectancy at the beginning of the treatment and improvement at the intermediate test. These results are in contradiction with those of Stern and Marks (1973), who found no significant correlations between expectancy and improvement with agoraphobics. In the present'study, however, the evidence in favour of 'expectancy' is only of a correlational kind. Only further controlled clinical trials in which 'expectancy' is employed as an independent variable can clarify the part played by expectancy. 
Acknowledgement-A grant from the Netherlands Organization for the Advancement of Pure Research (Z.W.O. no. 58-20) made this study possible. We wish to thank Kees Boersma. Peggy Cohen. Ank Emmelkamp-Benner. Paul Goudena. Simon den Hengst and Paul Schreurs for their assistance in the treatment of the clients and Roos Boink serving as an independent observer.

\section{REFERENCES}

AgRas W. S., Leitenberg H. and Barlow D. H. (1968) Social reinforcement in the modification of agoraphobia. Archs gen. Pslchiat 19, 423-427.

BORKOVEC T. D. (1973) The role of expectancy and physiological feedback in fear research: a review with special reference to subject characteristics. Behat. Therapy 4, 49!-505.

Crowe M.. Marks I. M.. Agras W. S. and Leitenberg H. (1972) Time-limited desensitization. implosion and shaping for phobic patients: A cross-over study. Behat. Res. \& Ther. 10, 319-328.

EMmFLKAMP P. M. G. (1974 a) Self-observation versus flooding in the treatment of agoraphobia. Belat. Res. \& Ther. 12, 229-237.

EMMELKAMP P. M. G. (1974 b) Effects of expectancy on systematic desensitization and fooding. Europ. J. Behat. Anal. \& Modification. In press.

Emmel KamP P. M. G. and UlteE C. A. (1974) A comparison of 'successive approximation' and 'self-observation' in the treatment of agoraphobia. Behar. Therapy $\mathbf{5}$. In press.

Emmfikamp P. M. G. and Cohen-Kettenis P. T. (1974) Relationship of locus of control to phobic anxiety and depression. Submitted for publication.

Everaerd W.T. A. M., RukeN H. M. and Emmelkamp P. M. G. (1973) A comparison of flooding and successive approximation in the treatment of agoraphobia. Behat. Res. \& Theraps. 11, 105-117.

Geldek M. G.. Bancroft J. H. J., Gath D. H.. Johnston D. W.. Mathews A. M. and Shaw P. M. (1973) Specific and non-specific factors in behaviour therapy. Br. J. Psychiat. 123, 445-462.

HaND I. LAMONTAGNE Y. and MARKS I. M. (1974) Group exposure (flooding) in vivo for agoraphobics. $B r . J$. Psychiat. In press.

Marks I. M. (1972) Flooding (implosion) and alled treatments. In Behatiour Modification. (Ed. W. S. AGRAs), Little, Brown. New York.

Marks I.. Boulougouris J. and MARSET P. (1971) Flooding versus desensitization in the treatment of phobic patients: a cross-over study. Br. J. Psychiat. 119, 353-375.

ROTTER J. B. (1966) Generalized expectancies for internal vs external control of reinforcement. Psychol. Monogr. 80. $1-28$.

STaub E. (1968) Duration of stimulus-exposure as determinant or the effcacy of nooding procedures in the eljmination of fear. Behat. Res. \& Ther. 6, 131-132.

STERN R. and MARKS I. (1973) Brief and prolonged flooding: a comparison in agoraphobic patients. Archs gen. Psychiat. 28, 270-276.

WATSON J. P. and Marks I. M. (1971) Relevant and irrelevant fear in flooding: a cross-over study of phobic patients. Behat. Therapy. 2, 275-295.

WILKINS W. (1973) Expectancy of therapeutic gain: an empirical and conceptual critique. $J$. consult. Psychol. 40, $69-77$.

Willems L. F. M., Tuender-de HaAn H. A. and Defarks P. B. (1973) Een schaal om sociale angst te meten. Ned. Tijdschr. Psychol. 415-422.

Wolpe J, and LANG P. J. (1964) A fear survey schedule for use in behaviour therapy. Behav. Res. \& Therapy 2, $27-30$.

ZUNG W. W. K. (1965) A self-rating depression scale. Archs gen. Psychiat 12, 63-70. 